\title{
14 \\ The Geography of Human Liberation
}

\author{
Richard Peet
}

1978. Antipode 10 (3), 119-33. ${ }^{1}$

The experience of communism, as it has turned out in practice, forces radicals to reconsider what we have in mind when we speak of "social revolution". We can no longer evade the question "what do you mean by communism?" with the glib response that the nature of the future mode of social existence will be molded by revolutionary praxis. For revolutionary praxis is conducted by conscious people, and inevitably a part of this consciousness is a conception of the post-revolutionary society. If by "revolution" we indeed mean a complete restructuring of social existence, even a transformation in the nature of humans, we have to have a clear idea of our eventual social purpose and we have to make clear the possibilities and direction of human change. We also have to appeal to people on the basis of the justice of our purpose if we want their comradeship in the collective struggle against the existing mode of life. Yet this vision of the future communism is exactly the weakest component of the evolving Marxist science and politics. Silence allows people to assume that the existing forms of communism are what we intend, when for most of us they bear little resemblance to the alternative society we have in mind.

How can the eventual communism be effectively discussed? The construction of models of "ideal" societies has a prominent place in the anarchist and utopian socialist tradition (Berneri, 1950). This literature is not devoid of ideas ${ }^{2}$ although most utopias warrant Engels' severe criticisms (Engels, 1892). Projections of the eventual nature of communism have to avoid making exact specifications of how things should be - this is idle and arrogant speculation. Also, such projections have to be made out of the dynamic of the decay of existing societies: that is, communism will emerge from a

\footnotetext{
${ }^{1}$ Reprinted with permission from Richard Peet.

${ }^{2}$ For example Morris (1891).
} 
capitalism collapsing from the development of a set of contradictions particular to a certain "stage" of history. But more importantly, what kind of analysis can be used to justify a particular form of alternative society? Inevitably the mode of justification must consist of relating the proposed societal form to a conception of human "nature". Human "nature" is not meant to refer to a set of attributes which can be specified in exact detail and remain fixed over time. The term instead refers to a group of general tendencies in human characteristics which necessarily arise out of environmental and social relationships which support the continued existence of life. These tendencies are expressed differently at different times and in various places, but they do exist as definable, general characteristics. The construction of a conception of communism must therefore proceed by isolating these tendencies, then projecting them into a societal form in the context of a particular dynamic of events in the decline of an existing social formation.

Attempts to do something like this have been made in the two main revolutionary traditions: Anarchism and Marxism, specifically by their main theorists Kropotkin and Marx. Although using vastly different philosophical modes, the two reached conclusions which are similar in certain aspects. At least, the similarities are sufficient to hold forth the prospect of the eventual development of a synthetic form of radicalism: an anarcho-marxism dedicated to achieving the communist basis of human liberation.

\section{Kropotkin}

Kropotkin's conception of human nature is derived from his empirical investigations into the evolution of the natural world. These "empirical" investigations were, however, conducted under a certain philosophical purpose. For Kropotkin, the vital need of modern society is for "a new, realistic moral science" founded on an ethical system which not only offers an explanation of the origins of the "moral instinct" but also provides a criterion for judging it, for advising where that instinct leads. Where can this system be found?

If the study of Nature has yielded the elements of a philosophy which embraces the life of the Cosmos, the evolution of living beings, the laws of physical activity, and the development of society, it must also be able to give us the rational origin and the sources of the moral feelings. And it must be able to show us where lie the forces that are able to elevate the moral feeling to an always greater height and purity (Kropotkin, 1947, $5) .^{3}$

\footnotetext{
${ }^{3}$ For a discussion see Galois (1976).
} 
But nature does not immediately appear to be characterized by the "good" and the "moral" and at once Kropotkin was faced by the common interpretation of Darwin that nature was a battlefield on which there was an incessant struggle for life, an extermination of the weak by the strong: "evil was the only lesson which man could get from Nature" (Kropotkin, 1947, 12).

\section{Kropotkin's Conception of Human Nature}

In response, Kropotkin argued that Darwin had indicated another set of facts parallel to those of mutual struggle: the facts of mutual support within the species, more important than struggle because of their significance for the welfare and maintenance of the species. Kropotkin himself then developed, through empirical research, the principle of mutual aid as the primary factor in the progressive evolution of both the animal species and the human race.

In the animal world, he argued, the vast majority of species live in societies and find, in association, the best means in the struggle against unfavorable natural conditions. Those animal species in which individual struggle has been reduced to its narrowest limits, and the practice of mutual aid attained the greatest development, are invariably the most numerous, the most prosperous, and the most open to further progress. "The mutual protection which is obtained in this case, the possibility of attaining old age and of accumulating experience, the higher intellectual development and the further growth of sociable habits, secure the maintenance of the species, its extension, and its further progressive evolution" (Kropotkin, 1910, 293). Mutual aid has thus become a permanent instinct (as deeply seated as the instinct of maternal love) which is always at work in all social animals, and especially man ${ }^{4}$. Kropotkin conceived of the history of mankind as the evolution of the tendency to organize life on the basis of mutual aid, first within the tribe, then in the village community, later in the medieval city. Even under capitalism, the mutual aid tendency cannot be broken it reappears in an infinity of associations embracing all aspects of life. In mutual aid, Kropotkin thus found the origin of "those feelings of benevolence and of that partial identification of the individual with the group which are the starting-point of all the higher ethical feelings. It is upon this foundation that the higher sense of justice, or equity, is developed, as well as that which it is customary to call self-sacrifice" (Kropotkin, 1947, 16).

In the Kropotkin conception, humans inherited from their animal predecessors the instinct of cooperative altruism: they are naturally social animals. In fact he argues further that human life is impossible without the intensity and variety of sensations

${ }^{4}$ Editors' note: At the time this article was written, sexist language of this kind was common. We decided not to correct the original use of language to ensure that the text remains readable. 
provided by social life. Physical, intellectual, and moral progress depends on the level to which sociality is developed:

... the practice of mutual aid and its successive developments have created the very conditions of society life in which man was enabled to develop his arts, knowledge, and intelligence; ... the periods when institutions based on the mutual-aid tendency took their greatest development were also the periods of the greatest progress in arts, industry, and science (Kropotkin, 1910, 296).

Yet humans are also competitive individuals, attempting to gain personal or caste superiority. They have also inherited feelings which induce them to subdue others, to utilize them for their own, individual ends. The two sets of feelings struggle between themselves, resulting in societies characterized by both cooperativism and competitivism, in societies dominantly cooperative with some competitive aspects or societies dominantly competitive yet dependent on cooperation. "The struggle between those forces make, in fact, the substance of history" (Kropotkin, 1910, 295). And the principle problem of ethics is to help mankind find the solution for this fundamental contradiction. It is only through establishing a certain harmony between the individual and all others that an approach to a complete life will be possible.

\section{Anarchist Communism}

Kropotkin places great emphasis on the role of ideas in the generation of revolution:

There are periods in the life of human society when revolution becomes an imperative necessity, when it proclaims itself as inevitable. New ideas germinate everywhere, seeking to force their way into the light, to find an application in life; everywhere they are opposed by the inertia of those whose interest it is to maintain the old order; they suffocate in the stifling atmosphere of prejudice and traditions ... The conflict between new ideas and old traditions flames up in every class of society, in every possible environment, in the very bosom of the family ... Those who long for the triumph of justice, those who would put new ideas into practice, are soon forced to recognize that the realization of their generous, humanitarian and regenerating ideas cannot take place in a society thus constituted; they perceive the necessity of a revolutionary whirlwind which will sweep away all this rottenness, revive sluggish hearts with its breath, and bring to mankind that spirit of devotion, selfdenial, and heroism without which society sinks through degradation and vileness into complete disintegration (Kropotkin, 1970a, 35-36). 
However, revolutionary ideas find acceptance because the economic and social structure of capitalism is already disintegrating from the competitiveness which drives it:

Human society is seen to be splitting more and more into two hostile camps, and at the same time to be subdividing into thousands of small groups waging merciless war against each other. Weary of these wars, weary of the miseries they cause, society rushes to seek a new organization; it clamours daily for a complete remodeling of the system of property ownership, of production, of exchange and all economic relations which spring from it (Kropotkin, 1970a, 36).

There is an incessant call for reform, yet everything cannot be reformed at once for this would mean, in effect, revolution. Hence the various government bodies initiate a series of half measures that satisfy nobody. A revolutionary situation arises. Through their activity the reformists are transformed into revolutionaries, by their example the masses are inflamed. "By actions which compel general attention, the new idea seeps into people's minds and wins converts ... it awakens the spirit of revolt" (Kropotkin, 1970a, 40). The state and the ruling class respond with violent repression and finally "the revolution breaks out, the more terrible as the preceding struggles are bitter" (Kropotkin, 1970a, 41). In the revolution, the party which has been most effective in putting its ideas into practice, which has shown "the most spirit and daring," will be listened to, while purely theoretical parties will be pushed aside.

On what basis is anarchism proposed as the foundation of the postrevolutionary society?

As to the method followed by the anarchist thinker, it entirely differs from that followed by the utopists. The anarchist thinker does not resort to metaphysical conceptions (like 'natural rights', the 'duties of the State', and so on) to establish what are, in his opinion, the best conditions for realizing the greatest happiness of humanity. He follows, on the contrary, the course traced by the modern philosophy of evolution. He studies human society as it is now and was in the past; and without either endowing humanity as a whole, or separate individuals, with superior qualities which they do not possess, he merely considers society as an aggregation of organisms trying to find out the best ways of combining the wants of the individual with those of cooperation for the welfare of the species. He studies society and tries to discover its tendencies, past and present, its growing needs, intellectual and economic, and in his ideal he merely points out in which direction evolution goes. He distinguishes between the real wants and tendencies of human aggregations and the accidents (want of knowledge, migrations, wars, conquests) which have prevented these tendencies from being satisfied. And he concludes that the two most prominent, although often unconscious, tendencies throughout our history have 
been: first, a tendency towards integrating labor for the production of all riches in common, so as finally to render it impossible to discriminate the part of the common production due to the separate individual; and second, a tendency towards the fullest freedom of the individual in the prosecution of all aims, beneficial both for himself and for society at large. The ideal of the anarchist is thus a mere summing-up of what he considers to be the next phase of evolution. It is no longer a matter of faith; it is a matter for scientific discussion (Kropotkin, 1970b, 47).

Kropotkin sees a growing popular criticism on the one hand of the increasing division of society into two classes leading to demands by the working class for their share of total production; and on the other hand "the very functions of government and the State, as also their relations to the individual, were submitted to a sharper and deeper criticism" (Kropotkin, 1970b, 49). The critique of the State includes centralized, socialist governments. It has become obvious that "a further advance in social life does not lie in the direction of a further concentration of power ... but in the direction of decentralization, both territorial and functional" (Kropotkin, 1970b, 51). Anarchism recognizes the justice of both of these tendencies, toward economic and political freedom, seeing them as different manifestations of the same need for equality which constitutes the very essence of historical struggle. It thus proposes a system based on free agreement and free cooperation, without sacrificing the autonomy of the individual to the all pervading interference of the State - what Kropotkin called "free communism."

In The Conquest of Bread and Fields, Factories and Workshops Kropotkin provides a detailed picture of the anarchist society which he saw emerging from the revolutionary process operating around the turn of the century (Kropotkin, 1913; 1901). He envisaged the development of a decentralized, worker self-managed production system, founded on an intensive mechanized agriculture with "workshops, foundries and factories ... within the reach of the fields. A variety of occupations, and a variety of skill arising therefrom, both working together for a common aim - these are the true forces of progress" (Kropotkin, 1913, 262). Property would be held in common with its product distributed according to need. Each commune would be basically self sufficient; that exchange which does take place would be made on the basis of agreements between communal production units. In such a system there would be no need for a State. The object is to produce a communal system which allows maximum freedom for the development of individual intelligence and inventiveness. For:

A revolution is more than a mere change of the prevailing political system. It implies the awakening of human intelligence, the increasing of the inventive spirit tenfold, a hundred fold; it is the dawn of a new science ... It is a revolution in the minds of men, as deep and deeper still, than in their institutions (Kropotkin, 1913, 265). 
Such a system, Kropotkin argues, is in accord with the findings of evolutionist philosophy: that the struggle for existence must be conceived not in its restricted sense of a struggle between individuals for the means of subsistence, but in its wider sense of adaption of all individuals of the species to the best conditions for collective survival as well as for "the greatest possible sum of life and happiness for each and all" (Kropotkin, 1970b, 53).

\section{Marx}

Marx evolved his conception of human nature, and his vision of communist society, within the philosophical context of dialectical materialism. From Hegel's Phenomenology of Mind, Marx derived the view that reality is not an external, objective datum, but is shaped by man through consciousness. However, while Hegel assumed that objects which appear to exist outside consciousness are, in the end, only a phenomenal expression of it, Marx accepted the existence of an independent natural substratum on which conscious man acts. As he interacts with nature, as he alters nature in the production of his life, man makes himself and shapes his relations with other human beings. The production of life involves a twofold relation, "on the one hand as a natural, on the other as a social relation - social in the sense that it denotes the cooperation of several individuals, no matter under what conditions, in what manner and to what end ... Consciousness is, therefore, from the very beginning a social product, and remains so long as men ${ }^{5}$ exist at all" (Marx and Engels, 1976, 4344). The basis of the man-nature interaction is that man satisfies his needs through his contact with nature; this act creates new needs, as well as the possibilities for their satisfaction. The never-ending dialectical pursuit of the creation and satisfaction of needs constitutes social-historical development (Avineri, 1968, 65-73).

\section{Marx's Concept of Human Nature}

Yet while man constantly makes, and remakes himself in interaction with external nature, and while different men interact with different natures in different places, there is basic structure to the man-nature relation which is common to all at all times. There is, as Ollman (1971, 75-6) argues, a Marxian conception of human nature in general ${ }^{6}$. This conception is erected as follows.

${ }^{5}$ Editors' note: the sexist language that appears in Marx' English texts is usually a matter of translation of the German term Mensch, which includes men and women but which is, grammatically, nevertheless male.

${ }^{6}$ Marx's "subject matter is not simply society but society conceived of 'relationally.' Capital, labor, value, commodity, etc., are all grasped as relations, containing in themselves, as integral elements 
Every human possesses certain needs and powers, some of which are "natural" (shared with every living entity) and some "species" (particular to humans). Need refers to the desire one feels for something external to the individual and usually not immediately available, while powers are changing abilities used to fulfill needs. As a part of nature, man has physical needs for objects required to keep him alive and functioning. He exercises his natural powers (labors, eating and sex) to fulfill these needs. But as a species apart from other animals, man pursues his activities in a way that could only be done by human beings: that is, "free, conscious activity is the species character of human beings" (Marx, 1963, 127). Natural powers establish the framework in which life goes on; species powers express the particular kind of life man carries on inside this framework (Ollman, 1971, 75-86).

The relations between man's powers and the world are the work of three interconnected processes: perception, the immediate contact man achieves with nature through his senses; orientation, how things are perceived and assessed; and appropriation, the use the powers make of objects to fulfill a purpose. In appropriation, humans make any object a part of themselves: if the appropriation is a significant one, it may enhance man's relations with the external world the next time around. Furthermore, one power frequently reacts on others making possible new achievements by these. Thus all man's powers move forward together, as a whole whose parts cumulatively interact. The degree to which this happens depends on the stage of development which the society has reached. For Marx, only communism makes possible the complete unfolding of the human "potential" (Ollman, 1971, 87-95).

In the autogenesis of man, activity (especially productive activity) plays the fundamental role:

The work-process $\ldots$ is human action with a view to the production of use-values, appropriation of natural substances to human requirements; it is the necessary condition for effecting exchange of matter between man and Nature; it is the everlasting Nature-imposed condition of human existence, and therefore is independent of every social phase of that existence, or rather, common to every such phase (Marx, 1961, 183-4).

For Marx, productive activity is man's life activity, the life of the species. It involves action by man's combined powers and it extends the boundaries in nature for the fulfillment of these powers. "By thus acting on the external world and changing it, he at the same time changes his own nature. He develops his slumbering powers and

of what they are, those parts with which we tend to see them externally tied" (Ollman, 1971, 12). Humans, in the relational view, are immersed in a set of interactions, influenced in their development by the totality of these relations (society), as individuals accumulating characteristics from their particular version of the whole. And the whole is constantly in motion. Each social factor is internally related to its own part and future forms, as well as to the part and future forms of surrounding factors (Ollman, 1971, 12-42). 
compels them to act in obedience to his say" (Marx, 1961, 177). Production is also the area of life where man's social character emerges most clearly. If productive activity is to succeed in satisfying man's basic needs, it must involve a division of labor, a cooperation with others, a dependence on the social whole. Man makes himself through the act of production in the context of a web of cooperative relations with others. He is necessarily a social animal.

Marx then projects this argument into a vision of what man can become under communism. All man's efforts, products, thoughts and emotions relate him to others. In communism such ties between people are strengthened to the point of transformation. Need or enjoyment lose their egotistical character. Communist man thus has a working conception of self as an extension of others. Within this net of social relations, the individual undertakes free conscious productive activity ("life engendering life"). Work which is willed, purposive, physically and mentally flexible, concentrated and social expresses what man is and develops his capacities not only to work but in the other spheres of life as well. Under communism man can assert his true individuality - that is, he may reach the height of his powers and needs, in cooperation with his fellows and appropriating all of nature (Averneri, 1968, 65-95, 220-39).

\section{Communism}

For Marx, the exact nature of the eventual communist society will be determined by the specific conditions under which it is established. Communism emerges out of a capitalism collapsing from the effects of its internal contradictions; but capitalism does not disappear suddenly, or completely, to be replaced by a social formation already perfectly formed. Hence the early "crude communism" must develop "economically, morally and intellectually, still stamped with the birthmarks of the old society from whose womb it emerges" (Marx, 1947, 24) ${ }^{7}$. In particular early communist man will not be able to escape completely from the effects of the property relations and necessarily materialistic values of capitalism. It is true that under crude communism, socialization of the means of production places the ownership of property into the hands of the State, and that surplus value is diverted into economic development and social services. But wages are paid according to the labor contributed, hence inequality based on differential productivity (what Marx called the principle of "bourgeois right") remains. And an incomplete emancipation of consciousness from domination by the products of labor makes it a vulgar, philistine and materialistic communism. "Immediate physical possession seems to it the unique goal of life and existence" (Marx, 1963, 153).

\footnotetext{
${ }^{7}$ On the transition to communism and the coming of "authentic man" see Koren (1973).
} 
This is, however, only a transitory phase in the passage to true communism. Marx does not discuss the dialectics of the dissolution of the crude form and the emergence of true communism. But, in the context of a discussion on ownership of the means of production and the distribution of the social product, Marx typically concentrates on a transformation of the labor process as the key to a more general social revolution (to a new, higher level of communism):

In a higher phase of communist society, after the enslaving subordination of individuals under division of labour, and therewith also the anti-thesis between mental and physical labour, has vanished; after labour has ceased to be a means of life and has become itself the primary necessity of life; after the productive forces have also increased with the all-round development of the individual, and all the springs of cooperative wealth flow more abundantly - only then can the narrow horizon of bourgeois right be fully left behind and society inscribe on its banners: from each according to his ability, to each according to his needs (Marx, 1947, 26-27). ${ }^{8}$

True communism thus involves eventually abolishing the division of labour in the sense of each person being forced into a particular, exclusive sphere of activity. In The German Ideology, Marx's discussion of labor under communism describes a society in which individuals are involved in a number of different kinds of production, developing a diverse ability and knowledge, including the re-integration of the development of mental and physical attributes (Marx and Engels, 1976, 47). This is made possible by a high level of social production, using a sophisticated technology. But the key to the reconstruction of life is control over the labor process, the process by which life produces life. ${ }^{9}$ With production and the products of labor (including new means of production) under social control, the alienated forms of life can be stripped away, and the process of reconstructing real social life, in harmony with nature, may be begun:

The positive supersession of private property, as the appropriation of human life, is, therefore, the positive supersession of all alienation and the return of man from religion, the family, the state, etc. to his human, i.e. social life ... the social character is the universal character of the whole movement; as society itself produces man as man, so it is produced by him. Activity and mind are social in their content as well as in their origins; they are social activity and social mind. The human significance of nature only exists for social man, because only in this

\footnotetext{
${ }^{8}$ Note that this was not written by the young Marx but in 1875 towards the end of Marx's life.

${ }^{9}$ Editors' note: The original text contains a footnote to "Marx, Capital, Volume 3, p. 800", but it does not reference this footnote in the text.
} 
case is nature a bond with other men, the basis of his existence for others and of their existence for him. Only then is nature the basis of his own human experience and a vital element of human reality. The natural existence of man has here become his human existence and nature itself has become human for him. Thus society is the accomplished union of with nature, the veritable resurrection of nature, the realized naturalism of man and the realized humanism of nature (Marx, 1963, 156-157).

In such a context, freed from relations characterized by mere possession, "Man appropriates his manifold being in an all-inclusive way, and thus as a whole man" (Marx, 1963, 159). The supersession of private property, the release from "universal exploitation of human communal life" allows:

The complete emancipation of all human qualities and senses. It is such an emancipation because these qualities and senses, have become human, from the subjective as well as the objective point of view. The eye has become a human eye when its object has become a human, social object, created by man and destined for him. The senses have, therefore, become directly theoreticians in practice. They relate themselves to the thing for the sake of the thing, but the thing in itself is an objective human relation to itself and to man, and vice versa. Need and enjoyment have thus lost their egotistic character and nature has lost its mere utility by the fact that its utilization has become human utilization.

Similarly, the senses and minds of other men have become my own appropriation. Thus besides these direct organs, social organs are constituted, in the form of society; for example, activity in direct association with others has become an organ for the manifestation of life and a mode of appropriation of human life.

It is evident that the human eye appreciates things in a different way from the crude, non-human eye, the human ear different from the crude ear. As we have seen, it is only when the object becomes a human object, or objective humanity, that man does not become lost in it (Marx, 1963, 160).

The senses of social man are thus different from those of non-social man. They are heightened by the humanized nature of his new mode of social existence: "the fully constituted society produces man in all the plenitude of his being, the wealthy man endowed with all the senses, as an enduring reality" (Marx, 1963, 162). Communist man's needs are intensified and widened. He becomes a man who "needs a complex of human manifestations of life, and whose own self-realization exists as an inner necessity, a need" (Marx, 1963, 165). And especially communist man needs the other person.

Communist man is enabled to free himself from the concept of god, which is a mystification of the process by which life is created: 
Since, however, for socialist man the whole of what is called world history is nothing but the creation of man by human labour, and the emergence of nature for man, he, therefore, has the evident and irrefutable proof of his self-creation, of his own origins. Once the essence of man and of nature, man as a natural being and nature as a human reality, has become evident in practical life, in sense experience, the quest for an alien being, a being above man and nature (a quest which is the avowal of the unreality of man and nature) becomes impossible in practice (Marx, 1963, 166-167).

Communism is thus positive human self-consciousness. It is the phase of the negation, a real and necessary factor in the emancipation and rehabilitation of man in preparation for the next stage in historical development.

\section{Kropotkin and Marx}

In terms simply of their descriptions of human nature, and the eventual communism, Kropotkin and Marx are surprisingly similar. Both see cooperation as fundamental to social and individual human development. They agree on such essentials as collective ownership of the means of production; abolition of the wage system; distribution of the social product according to need; even, perhaps, a "naturalistic" communism. Yet they reach their conclusions via completely different modes of philosophical inquiry, Kropotkin using a naturalistic (evolutionist) philosophy, Marx a dialectical penetration to the material origins of human existence. Thus for Kropotkin, humans are innately (instinctively) cooperative and communism is the natural form of social organization, while for Marx human sociality is the necessary result of a collective effort to produce the material basis of life and communism "the necessary form and the dynamic principle of the immediate future" (Marx, 1963, 167). Does this dependence on different philosophical traditions mean that the two great radical traditions are irreconcilable? Not necessarily, if a major addition is made to Kropotkin's theory of human nature.

\section{Culture}

Kropotkin's immediate intention was a theory of evolution which would counteract the Social Darwinist theories of human evolution current in Europe in the late nineteenth century. For this purpose he constituted a natural-evolutionist theory which, when it came to human history, over-played the role of natural sociality and mutual aid in human cooperation. Thus, human culture is seen as the direct expression of the natural qualities of man. But whether in the modern form of sociobiology, or the benign Kropotkin form, "biology, while it is an absolutely necessary condition for culture, is equally and absolutely insufficient: it is completely unable to specify the 
cultural properties of human behaviour or their variations from one human group to another" (Sahlins, 1977, xi). What is missing from Kropotkin's formulation is the conscious inclusion of the concept of culture at the heart of his theory of human development.

This is not the case with Ashley Montague who, while following Kropotkin in that "Man is born for cooperation, not for competition or conflict" (Montagu, 1960, 109), places culture at the centre of the process of human evolution:

With the creation and usage of organized systems of symbols man created a new dimension of experience which at the same time yielded him an increasing control over his environment. This new dimension of experience we call human culture. Man-made culture is the special kind of environment man creates the better to control as much of the general environment as he desires (Montagu, 1968, 102).

Culture is a new dimension in the relations between organisms and their environments, in which man creates and directs his own adaptation. The culture concept can be synthesized with ongoing biological selection (Montagu, 1968, 105), yet its advantage is that:

Culture ... represents a biological adaptation, based on genetic changes, but transmitted non-genetically, that is, through the socially interactive process of learning. Culture is man's social heredity. Within the limits set by the genes every human act of the organism is learned, acquired, through reaction of the culture upon him. Though based on genetic factors which make it possible, culture is itself an extra-genetic, a superorganic, system which functions in the serve of man, just as any tool does, to enlarge and extend the satisfaction of his needs (Montagu, $1968,106)$.

Culture, then, is the missing dimension to Kropotkin's theory of human evolution. The culture concept takes the emphasis off innateness and accumulation of experience. It is a mediating factor in the dialectic between the human organism and the natural environment. ${ }^{10}$

In this dialectic humans, as all organisms, incorporate the environment into themselves as the material source of life. Sociality is the permanent (but changing) characteristic of this dialectic, the source of sexual reproduction, and a more efficient material relation with the environment, so necessary that it must become instinctive.

${ }^{10}$ Belasco (1975) outlines the process of evolution as a complex whole composed of biological, socio-cultural and environmental factors: "the interaction of these variables constitutes a dialectic i.e., a movement of successive contradictions between, and resolutions of, neuroanatomical and cultural (as evidence $\{\mathrm{d}\}$ by tools) development, in the context of environmental imbalance and equilibria." 
But the source of difference between humans and other organisms is that humans consciously produce their means of new life through the application of collective labor to the environment. ${ }^{11}$ Their material-production-based culture is then passed on through the institutions of the society and learnt by new individuals entering that society. This process of the integenerational transmission of knowledge in learnedforms enables the accumulation of a more sophisticated culture; and the learning of this accumulated culture becomes the most important process in the formation of human "nature." Culture is the collected experience of the collective past and the bond which holds people in the present into collective wholes. It is the special human form of sociality.

\section{Anarcho-Marxism}

A synthesis between anarchism and Marxism is yet to be made. While it is beyond this paper, it is not an impossible task. It is necessary on the one hand to add the power of dialectical-materialist analysis to an anarchism which too often relies either on naturalistic arguments or emotional polemic; and on the other hand to make Marxism culminate in the politics of human liberation rather than in sterile dogmas which enable it to be seriously proposed that "the fight... against the ideas of the freedom of the individual ... has been a consistent one throughout the history of the Marxist movement" (Leach, 1978, 36).

In outline form, anarcho-marxism might consist of the following theoretical structures:

1. An overall philosophy based on the dialectical analysis of evolution seen as an interaction between organic life and the natural environment. The necessary form of this interaction is the incorporation of the material environment into the life of each organism.

2. In the animal world, the banding together of members of a species into cooperative groups yields such material and reproductive advantages in the interaction with the rest of nature that sociality becomes a dominant instinct, an instinct which is shared by humans.

3. Humans evolve a culture composed of the accumulated experience of the collective past which intercedes as a mediating factor between their neuroanatomical make-up and the environment. Culture is transmitted within

${ }^{11}$ Or as Engels $(1975,4-5)$ put it: "The mastery over nature, which began with the improvement of land, with labour, widened man's horizon at every new advance. He continually discovered new, hitherto unknown, properties of natural objects. On the other hand, the progress of labour necessarily helped to bring the members of society close together by multiplying cases of mutual support and joint activity, and by giving each individual a clearer consciousness of the advantage of this joint activity." 
cooperative groups via the learning process (leading to a social - rather than a natural - scientific approach in the study of human characteristics and societies).

4. Human culture is structured by the dominant life activity - production. It is formed in the relations of production and is understandable within the analysis summarized by Marx $(1970,20-27)$ in his preface to A Contribution to the Critique of Political Economy.

5. Capitalism, as all modes of production, is based in human cooperation, yet ownership is vested in a ruling minority. This perversion of cooperation is the basis of its central contradiction which then underlies a whole structure of destructive contradictions (including contradictory relations with the natural environment).

6. Contradictions intensify and interact over time and tend towards the disintegration of capitalism. The main counteracting force is ideology which under capitalism acts to promote false consciousness. False consciousness has penetrated the human mind to such an extent that only the devastating crises of mature societal contradictions can penetrate through it (Peet, 1979).

7. The revolution made possible by the dissolution of false consciousness has, as its main aim, social ownership of social production - collective control over the collective process in which human life is formed.

8. But vesting control in the state replicates the contradictory relationship between cooperative production (at a small scale) and ownership and control of the means of production (at a large scale) and leads to a form of centralized "communism" which is forced to rely on the ideological and violent oppression of its population.

9. Therefore, a decentralized, worker-controlled communism is the socioeconomic form of the post-revolutionary future.

This structure of ideas, in combination with Marx's and Kropotkin's theories of human nature and communism, is the basis of the analysis of contemporary capitalism, and its negation, which follows.

\section{Contemporary Capitalism}

In the last two decades, capitalism has definitely moved into its final stage - the era of mad consumption. This intra-capitalist transformation began when social production mainly to satisfy needs was left far behind and the system began to rely on created wants, then created "needs," to maintain the accumulation of capital. The economic basis of this transformation has been described as follows: 
When social output is relatively low and necessary consumption absorbs a large part of it, the immediate material requirements of social reproduction exercise a decisive influence on production - i.e. the bulk of production must be devoted to basic items of personal consumption. In this context the process of accumulation can appear as an effort to expand production for the sake of increased consumption. But as production expands under the impetus of accumulation and the proportion of it required for necessary consumption falls, the material requirements of social reproduction no longer exert the same decisive influence upon it. Capital gains much greater room for manoeuvre and as the value aspect of production comes to the fore the real nature of accumulation as the pursuit of pure quantity is revealed. But not to the representatives of capital: what class could ever recognize that its social practice is utterly absurd in human terms (Kay, 1975, 75)?

What this statement does not analyze is the effect such a change has had on culture and the social psychology.

The ability of the production system to turn out commodities far beyond the level of natural needs, and the necessity within capitalism of constantly pushing forward all the frontiers to accumulation at once, made it imperative that the level of consumption be continually revolutionized in the advanced capitalist countries. This imperative compelled a transformation in the level and sophistication of the manipulation of culture and of the human mind and emotions. In particular, the continuation of accumulation was possible only by "commoditizing" the person - that is getting people to express even their most subjective needs and wants primarily in commodity forms, transforming wants into "needs" to deepen people's reliance on the commodity habit, and thus changing people to the extent that continually adding new commodity wants became the major dynamic, literally the main object, of life. Work and religious values, tied to past stages in the capitalist mode, were transformed into the new consumption "values." Old culture forms oriented towards the discipline of production were made over into new, stressing consumption (which itself is a form of industrial discipline). And while the ruling class took advantage of the situation, its technocracy managed and propagated it, and nearly everyone joined in the rush to consume, the process occurred on the whole as the consequence of blind forces emanating out of the nature of economic expansion - that is from the very process of capital accumulation, as its necessary expression in culture.

But in every such process there is a contradiction. In the era of mad consumption, capitalism came into a heightened contradictory relationship with its earth environment. For, to keep up with the extraordinary level of commodity production, capitalism is forced to strip the earth of its resources and pollute its beautiful face with the abundant refuse excreted by an over-consuming society. Capitalism has always been characterized by destructive contradictions; indeed its development as a system is propelled by the evolving interaction of the internal 
elements of its great contradictions and, more recently, the clash between one contradiction and another. But the contradiction with earth, latent always in the nature of capitalist production, but never so fully realized as in the era of mad consumption, adds a new and more fearful dimension. For, whereas before, contradiction was the basis of social change, the addition of an exaggerated conflict with environment now threatened our social survival - in the sense that we are destroying what we rely on for our life. It is a contradiction dangerous in itself. But more than that, environmental contradiction interacts with the other, more familiar social and economic contradictions of capitalism making them worse, and these in turn deepen the conflict with environment. ${ }^{12}$ It is the interaction of contradictions, the growth of complexes of contradictions (now focused on resources and environment), that characterizes the late stages of capitalism. Ever-more dangerous "solutions" are proposed in a desperate effort to escape. Ever-more threatening, unproven technologies are used in an effort to maintain existing life-styles, while it is those very life-styles which cannot be supported by earth resources. The people of the capitalist systems do not grapple with the source of their problems: escapist ideologies and over-consumption-while-there-isstill- time, permeate a lost people.

\section{The Relational Basis of the Formation of Personality}

Let us consider, yet once more, that the essential framework of life must be our relationship with nature, and with other people, organized around the principle of the reproduction (the perpetuation) of life. The key social form which these relationships take is cooperative production (or, in its individual form, work). In work we relate to others in an effort to gain from the earth enough commodities for our survival: to meet our needs. Production provides the material basis of social reproduction and thus exerts a determining influence (understood in a dialectical rather than a mechanisticdeterminist way) on culture, social forms, and personality. We cannot say that we control ourselves when we do not collectively control our mode of production. Social control over production is necessary if a people are to control the material framework in which their lives unfold.

The essential relationships of life thus evolve around the production of its material base. These relations are the basis of our survival, and it is through them also

${ }^{12}$ For example, while economic depression is a common occurrence in capitalism (stemming from the class nature of the capitalist system) and conflict between inflation and unemployment a common problem in capitalist economic policy, the depression of the 1970s poses particularly severe problems. For depression interacts with resource scarcities produced by prior over-consumption. As a result, Keynesian policies designed to stimulate employment face a particularly sharp inflation response, while at times the energy resources needed to support economic growth are physically unavailable. The result - calls for the use of nuclear technology capable of inflicting damage to the environment that would make life impossible. 
that we develop ourselves as individuals. The people, objects, ideas, processes that we encounter during our essential relationships possess qualities, and through our interaction we incorporate some aspects of these qualities into ourselves; there they interact one with another to produce hybrid qualities, unique people. Qualities accumulate as experience and new qualities, taken in during new relationships, play on already characteristics, continually altering the form that these take. Internal relations (within the person) are thus conditioned, but not mechanistically determined, by external relations (between person and total environment). Different modes of production, even different epochs within a mode, structure external relations differently and thus condition the growth of personality differently; that is, place parameters on its probable development.

The mode of production generates an environment of ideas and objects (animate and inanimate) which exists prior to our arrival and which we at first can do little to change. This environment should contain diverse qualities which potentially interact with, and develop, the various facets of ourselves. But diversity needs to be combined with depth, or intensity, of interaction (with the implication that it is impossible to establish deep interactions with superficial versions of objects or processes).

That is, during our interactions with any piece of the external would we must derive a variety of qualities, each quality appreciated in its many nuances, and each incorporated into ourselves at an emotional as well as an intellectual level. For this type of relationship to develop, humans, as they are at the present time, need long-term and frequently repeated contacts with any piece of the external environment: we cannot develop many such relationships simply because we do not have the time to do so. Diversity and intensity of experience thus tend to be contradictory. What is clear however, is that we must arrange the structure of the essential relationships of our lives in ways which will promote intensity and depth of experience to enhance the qualitative effect these have on our development as subjective, feeling, creative people. At the same time, but within this context, we should also provide diversity of interaction and experience. Diversity of intense experience is the overall objective. And it is here that capitalism fails abjectly, for on the one hand extreme specialization of function and homogenization of life have restricted diversity of experience, while on the other the "advanced" technology of capitalism has been used to condition experience and make it shallow.

\section{The Effects of Ideology on the Capitalist}

Yet there is more. We accumulate our internal culture in part from the ideas passed on to us (the results of past experience), and in part from the particular present experiences that we have. In the advanced form of capitalism both are subjected to the lost sophisticated manipulation, and have been over considerable time periods. This manipulation has taken a particularly perverse direction in the era of advanced 
commodity capitalism. The present mode of life is characterized overwhelmingly by a lack of real content, for the content of life has long ago been drained off into the Commodity. Thus, for example, between person and natural environment intrudes the Commodity and between person and person slips the iron veil of commoditized appearance. Person interacts via consumption with anonymous system which interacts (manipulates) with person. Cut off from its relational roots, real life dissolves ... and is replaced by the ideology of life, a commodity of the mind expressed in terms of physical commodities and "super-people" (artificial images of fantastic peoplecommodities). And the "minds" that dream up the new ideologies trappings of life are themselves the products of a previous version of that ideology. Ideology has finally spun off to become a thing virtually unto itself. It makes us as its images, and we feed it with our "selves." What we are given, in the form of appearances, does not satisfy us (faint signs of life remain); but instead of rediscovering what is real, and rejecting imposed images, we move on adding new places, new styles, new "people" to our esoteric "personalities." And so we must, for it is exactly the precarious logic of capitalism that we fail to find the meaning of life in consumption, rather than looking where it lies, in production. For it is this failure, and our consequent constant search through commodities, that keeps commodity circulation going and capital accumulating. So we have "progressed" from simple capitalism, through alienation and commodity fetishism, to the present relation between the image of the person and the ideology of a society. We, the people produced by this most damaging stage of a destructive system, must now ask what we are, and how we can find ourselves again?

Such questions bring into focus once more that stream of radical thought called anarchism. The aim of anarcho-communism in the present era of cultural manipulation is to allow people to re-contact the most basic of life-forming processes. It allows the reformation of our ideas about ourselves in the raw environments of direct natural and social relationships. It is an attempt to construct a geography of human liberation. At the present time it is also drastic human therapy.

\section{Components of Anarchist Decentralization}

Decentralization means reducing the scale of every-day life, reducing the number of interrelationships, deepening the intensity of each relationship, and allowing people to find a nature for themselves in the context of direct relations with the social and natural environments. Decentralization is an attempt to socio-spatially re-arrange the mode of production to promote an environment of intense, diverse social relationships, and a more natural world, in which the human personality can develop. Decentralization allows experience to develop and ideas to grow from direct contacts with the physical environment and the environment of others, instead of ideological versions of these contacts. It provides for the subjective, as well as the objective, satisfaction of needs. It istherefore particularly suited to the dissolution of the process of human commoditization. Decentralization, in the anarcho-communist sense, 
constitutes a new mode of production (Breitbart, 1975, 44-49). The main arguments for this mode are as follows.

\section{Control}

Behind the many aspects of social and psychological control exercised by capitalism over us, its people, is a fear we must have for the continuation of our lives. By stripping us of our independent means of production, capitalism created, at the same time, the pre-condition for capital accumulation and the basis of our psychological control. The ultimate terror we feel is the fear we have of those who depend on our labor not being able to survive because we can no longer work, or are not allowed to work, in the existing system of production. Perhaps only the possibility of none of us being able to survive, because of imminent collapse of that entire system, can arouse us from our present paralysis. By contrast, a people which directly controls the means of producing the material basis of survival has the confidence to be free. And only such a people controls the means by which they are made human. Communist decentralization, therefore, is a technique designed to give back control over the basic processes of life to the people who inhabit those processes. The principle of such a radical decentralization is that a people-group should rely on itself that is, it should be able to make its life out of what it produces, and structure its culture essentially around the materials of its immediate environment. At its logical conclusion, decentralization must imply the capacity to be self-sufficient - at a number of scales. Each individual should be able to produce enough food and shelter for survival, each family enough for a simple comfort, each group enough for stability and diversity of consumption. Except in time of extreme environmental stress, trade should be relied on only to add more diverse elements to the material supply, although it may be valued also for the contacts it entails with others. As we make ourselves into new kinds of people, dependence on others via trade may be increased. But the idea of valuing self-sufficiency as the basis of a non-dependent freedom, a people making itself, remains the underlying objective of a decentralized, communist mode of production.

\section{Collectivity}

Decisions over the direction of economic and cultural development are made, in the end, by the owners of the means of production. A people wishing to control itself must own the means of production directly - that is, the workers in any institution of collective production must themselves control that institution, and not do so via the intermediary of the State, either as owner or controller of the means of production. And further, institutions should not be so large that all their members cannot, when necessary, meet and argue on issues which vitally concern their existence. It is impossible for all to agree completely on every decision, but it is not 
impossible to make decisions which all have affected if the scale of life is small enough. In such a system there is no need, no place, for permanent leadership. Leadership deprives a people of the opportunity to develop their own powers of decision-making. On the other hand, decentralized, collective decision-making is efficient in that the need for a non-producing bureaucracy does not exist, while in addition the people who are affected most, and have the most practical information, end up making decisions. Collective, localized decision-making is thus the logical corollary of the idea of self-sufficiency.

\section{Ethics}

Alienation and social irresponsibility in capitalist life result in part from interacting with an anonymous "system" rather than with real people who one knows. But a people producing and living together, relying on each other in a system of mutual aid, must develop intimate relations one with another, one with the whole. Decentralization thus provides both the purpose and the opportunity for new feelings about others to develop. Ethics may be thought of as a main force in the human revolution, the transformation of humans into new kinds of beings. But to carry out this overwhelming task, a people's ethics must come from the deepest source, which is the necessary way we relate to each other and to earth. And what is needed for our survival? Our mutual aid and cooperation! We have to rely on each other in a direct way and to relate to environment directly to find an ethics suited to the task at hand. We have to allow the original sources of ethical feeling to grow again.

\section{Diversity}

Different aspects of our relations with environment, and with others, produce different types of experience, and diverse experience develops the various facets of the human personality. But this does not happen in a facile way. The interaction with total environment has to be at the profound level of creating from it the means for the continuation of life. We cannot manufacture "experience" in the belief that we are creating "multifaceted people"; rather diversity has to be a component of the basic processes of the society. Hence, social production has to be re-organized to provide several kinds of production (agriculture, industry) in each commune, to permit a mix of several types of involvement (mental, physical) at any time in each sphere of production, with the purpose of permitting diverse kinds of experience. Anarchocommunists value the qualities they allow to develop in others, and in themselves, more than the volume of commodities produced. A fine quality of social existence makes easy any material sacrifice that may be necessary to accomplish it. People are more lastingly interesting than products! 


\section{Integration}

Capitalism yields a rich harvest of disintegrated lives as it separates the components of life into different social and spatial spheres. Decentralization aims at reintegrating, in small places, production and social reproduction, work and leisure, men, women, and children, old and young. Of these the basic re-integration is that of economic production with social reproduction. Not only should both occur in close proximity, with an exchange of people between, but as the purpose of production changes to one of allowing the creation of new kinds of people, so social reproduction can assume its true function (which is to raise children to meet the highest aspirations of the society) and be fully integrated with economic production. In these integrated activities there is no place for age or sex discrimination. Everyone is part of the production and reproduction of life, all have much to offer, all can get from this a sense of worth because all make a contribution to the whole.

\section{Creativity}

Under capitalism, creativity is separated from the every-day practice of life and made into a thing by itself, carried on by an artistic or technocratic elite, and transmitted back to dominate us as artifacts, products, ideas, or "super-people." Yet creativity stems, originally, from the nature of our relations with objects and with others in the production of life. Everyone who is involved in this great production thus works at the source of creativity, and has the opportunity to be creative, if the processes of life are re-organized on a small scale to allow the expression of individuality in all products and relationships. Decentralization can provide the opportunity for everyone to develop a natural creativity, one concerned with making more efficient, or more beautiful, the real activities one engages in.

Further, a people group struggling together in direct contact with each other, is a creative act in itself. It is a rich social environment for a new type of technology, one which makes production more efficient, but which considers "efficiency" in terms of total contribution to all the life objectives of the group. Creativity and technology are reintegrated into life in a decentralized system. We control our technology, everyone understands it, everyone contributes to its growth and shapes its direction. The aim of anarchist decentralization is to use our creativity to make a peoples' art and a peoples' technology.

\section{Naturalism}

Our present alienation from the natural environment stems immediately from the characteristics, the motives, of capitalism, under which the environment becomes merely a group of commodities - animals which we can relate to only by 
"humanizing" ("Disneyizing" in the advanced ideological phase), resources that we "tame," etc. In capitalism we relate to each other and to environment by trying to dominate, which is, of course, the crudest attempt at a relationship. Yet we are, in the end, dependent on the natural environment for the physical inputs necessary to preserve our existence. Inevitably we must enter into organic relations with environment, for we are, at last, organically related to it. Communist decentralization is a technique aimed at renewing direct relations with the natural world, of placing production and life within it, as part of it, by daring to make ourselves immediately dependent on the environment. When we have to live off one limited piece of earth we must enter into different forms of relationship with it, for we suffer from mistreatment in an immediate and forceful way. By depending on environment, by knowing its processes in intimate detail, by entering into these processes to maintain our life, we become again natural people, who perhaps can then be trusted to humanize nature.

\section{The Geography of Human Liberation}

A liberated people are free to collectively make of themselves what they want within the limit of not damaging others. To do this they must have the confidence which can come only from controlling their own means of production based on their own piece of earth environment. Decisions must be made collectively with all joining in. They have to be bound together, in a set of intimate relations, by mutual dependency; in mutual aid should they find their sense of ethical morality, and in ethics a mode of transcendence. Social production, as the main source of life experience, must be organized not only on the basis of its role of commodity output but also and dominantly, on the basis of its multiple effects on the people who work in it - especially it must provide intensity and diversity in every-day experience. The various components of life must be reintegrated into a whole life experience, conducted in a recognizable place, with creativity - the chance to make original contributions to others - at its core. And the whole social process should relax back into nature, as its human part: "the consummate oneness in substance of man and nature - the true resurrection of nature - the naturalism of man and the humanism of nature both brought to fulfillment" (Ollman, 1971, 110).

Anarcho-communism does not prescribe an exact way of life for people to lead. No-one can do this for anyone else. Few can do it exactly even for themselves. Anarchist decentralization merely presents magnificent, original opportunities for people to respond in their own ways. New lives and new people come from experiment, and decentralization describes the conditions under which a people is free to make its own mistakes, with only themselves suffering the consequences of their actions. Under the anarchist version of communism a variety of communal life-styles is probable, and any individual is free to live a number of different kinds of life either by an agreement to change by the people one lives among, or by moving to a more compatible group. Beyond freedom from want lies freedom from a fixed, determined self. The internal interaction of human qualities in dialectical interrelation with a 
complex of changing environmental stimuli forms an unlimited frontier for us to move into. Human "perfection," like outer space, expands without end. But we have to live in a social system which allows, encourages, processes of human perfection rather than discourages or perverts them. Anarchist communism tries to do this. Decentralization is its socio-spatial method.

\section{Contradiction and Revolution}

The major social, cultural and environmental contradictions of capitalism interact one with another and result in a rush of problems unsolvable within the structure of the system. As this complex of contradictions matures, as the problems of social life intensify, the system's protective ideological membrane can no longer hold back the development of true consciousness. Individuals and groups of people break away, begin to attack in various ways; ${ }^{13}$ some begin to live a life of cooperative selfsufficiency - a way of physically surviving and immediately beginning the reformation of self, living the revolution instead of merely talking about it. As consciousness is developed by the intensification of contradiction, and as it becomes physically impossible to survive within capitalism, the numbers of communes grow and the cooperative movement spreads, until it forms an alternative material base for a new life growing within the rapidly decaying body of the old. At this point we must expect capitalism to degenerate into a more obvious form of fascism: the contradictions of capitalism cannot be solved, but the effects of contradiction may be "ameliorated" through the use of physical, and extreme psychological, force. Finally, in the phase of capitalist collapse, when our rampant consumption is no longer supported by the raw materials and labor of the Third World, when shortages of fuel and food make it impossible to live, when the pollution (or the nuclear damage) of a failing "super-technology" is so severe that large areas have to be abandoned, when inflation is beyond control, when the level of crime and acts of alienated violence make whole cities uninhabitable, the alternative cooperative economy becomes the economy - the only one capable of ensuring the continuation of life.

If we survive the events of the next decades, what might this necessarily decentralized, cooperative economy look like?

${ }^{13}$ The intensification of contradiction in late capitalism makes several kinds of revolutionary activity increasingly realistic and fruitful. It may be that these kinds of activity will be capable of creating revolutionary change before capitalism disintegrates. My own analysis of the depth of the penetration of ideology into the human personality make[s] me skeptical, however, even though I support virtually any effort aimed at the overturn of the capitalist system. From my perspective capitalism will be abandoned only when its contradictions have matured to the extent that they make capitalist life physically impossible. 


\section{A “Return to Nature"}

The idea that history repeats itself is a simplified version of a fragment of the dialectic. The interpenetration of events, and the synthesis of the past into the present, precludes the possibility of historical repetition. The present always has certain similarities with the past, for it is its product: but it is also always new - the first moment in the rest of time.

Likewise, the idea that anarcho-communism represents an effort to return to a purified version of the past contains a faint truth but is, in general, inaccurate. Take, for example, the idea of the "return to nature," which is a component of much anarchist thinking. This will be the return of a people who, even by selecting from their nowabundant stock of technology, could be relieved of much of the drudgery of previous agriculture life. And the new small- and intermediate-scale technology, which even now begins to develop, can be labor-saving and at the same instant improve the quality of the time spent in work. The conception of future people which guides anarchist thinking is that people are capable of transcending over-consumption, recognizing that in terms of the individual it is caused by other, unsatisfied wants and needs, and in terms of the society by the need for capital accumulation. Anarchist decentralization is an attempt to satisfy needs directly, in the course of social life, rather than indirectly via commodity consumption. But beyond, or beneath, this discussion, [lies] our present capability to see the natural world as it is, to understand its processes as they are, to place ourselves within it scientifically instead of mystically. Our relations with the natural world may now be accurate and realistic. Our thoughts may now grow out of natural processes, may go beyond those processes but remain organically related to them. This time, when humans again become part of nature, the pattern of our lives can be both natural and distinctively human. Anarchist science is social, in that it considers the effects of its technology on the total quality of life rather than merely on "productivity;" is natural in that it attempts to place production into the context of environmental processes; and is organic in that its conception of social existence is one integrated into nature. Anarcho-communism therefore does not speak of a return to nature, but an advance to scientific, creative humans in nature. It is a new mode of natural life.

The anarcho-communist concept of landscape is organized around the principle of allowing people to retain direct contact with the essential process of life - those related to the production and reproduction of the species. Communities, ranging in size from a few people to several thousands, first produce the food and shelter necessary to maintain life and then specialize in production, services, and research suited to the local resources, their accumulated skills, or their synthesis of disposition and obligation to their fellow humans. The pattern of spatial interaction reflects a concept of social relations - intensive, frequent interaction with a sizeable group of trusted others and a wider network of less frequent contacts with diverse other groups. Contact with other groups is not via an anonymous price system, but is based on negotiated agreements (which might come in the guise of festivals - after all life is being 
exchanged for life). And following from this, while the basis of commodity/service exchange is labor (human life time) content, exchange ratios are left fluid to allow for the expression of communal need. Eventually exchange is based only on need as communal consciousness bursts into total humanity consciousness.

In the anarcho-communist collective everyone works a part of the day to harness the renewable natural resources of the locality for the purpose of keeping human life in existence. During the physical labor of food and fuel production people daily renew their contact with the natural world, with their predecessors who have worked the land, with the future generation which that land will support. Food production is the nexus of environmental and spatial relations which extend through time. It places the individual's life in a socio-temporal continuum continually connecting momentary experience now, in a deja $v u$ way, with similar moments in the past, and in a visionary way with the experience of others in the future. It is a fitting context in which anarcho-communist life can develop for it provides the basis of independence and the guarantee of freedom, which in turn allow an open, noncompetitive relationship with others. In the future, even the crumbling cities of a past capitalist age, (where some production facilities are kept going by the workers' syndicates), should produce the food basis of their survival with the use of intensive gardening techniques. Yet overall, the future decentralized landscape will have to be a village and town society, one which can be based primarily on regional resources that are renewable, a low-energy system run by wind, water, sun and vegetation using a sophisticated but natural technology. It will be a society which finds that the satisfaction of physical needs could be done relatively easily, but chooses to do so in a delicate way, for in the mode of satisfying need we find the source of our greatest challenges and, at the moment, our most disastrous mistakes.

\section{References}

Avineri, Shlomo. 1968. The Social and Political Thought of Karl Marx. Cambridge University Press.

Belasco, Bernard. 1975. On the dialectics of human evolution. Dialectical Anthropology 1(1), 86-90.

Berneri, Marie Louise. 1950. Journey through Utopia. London: Routledge and Kegan Paul.

Breitbart, Myrna. 1975. Impressions of an Anarchist landscape. Antipode 7 (2), 44-49.

Engels, Frederick. 1892. Socialism: Utopian and Scientific. London: George Allen and Unwin. 
Engels, Frederick. 1975. The Part Played by Labour in the Transition from Ape to Man. Peking: Foreign Languages Press.

Galois, Bob. 1976. Ideology and the idea of nature: The case of Peter Kropotkin. Antipode 8(3), 1-16.

Kay, Geoffrey. 1975. Development and Underdevelopment: A Marxist Analysis. London: Macmillan.

Koren, Henry. 1973. Marx and the Authentic Man. New York: Humanities Press.

Kropotkin, Peter. 1970a. The spirit of revolt. In, Roger Baldwin (ed.), Kropotkin's Revolutionary Pamphlets. New York: Dover Publication.

Kropotkin, Peter. 1970b. Anarchist communism: Its basis and principles. In, Roger Baldwin (ed.), Kropotkin's Revolutionary Pamphlets. New York: Dover Publication.

Kropotkin, Peter. 1947. Ethics: Origin and Development. New York: Tutor Publishing Co.

Kropotkin, Peter. 1913. The Conquest of Bread. London: Chapman and Hall.

Kropotkin, Peter. 1910. Mutual Aid: A Factor of Evolution. London: William Hienemann.

Kropotkin, Peter. 1901. Fields, Factories and Workshops. New York: G. P. Putnams.

Leach, Bridget. 1978. Geography, behaviour and Marxist philosophy. Antipode 10 (2), 33-37.

Marx, Karl and Friedrich Engels. 1976. The German ideology. In, Marx \& Engels (eds.), Collected Works. London: Lawrence and Wishart.

Marx, Karl. 1970. A Contribution to the Critique of Political Economy. Moscow: Progress Publishers.

Marx, Karl. 1963. Economic and philosophical manuscripts. In, T. B. Bottomore (ed.), Karl Marx: Early Writings. London: C. A. Watts.

Marx, Karl. 1961. Capital: A Critical Analysis of Capitalist Production. Volume 1. Moscow: Foreign Language Publishing House.

Marx, Karl. 1947. Critique of the Gotha Program. Moscow: Foreign Language Publishing House.

Montagu, Ashley. 1968. On Being Human. New York: Henry Schuman. 
Morris, William. 1891. News from Nowhere. London: Reeves and Turner.

Ollman, Bertell. 1971. Alienation: Marx's Conception of Man in Capitalist Society. Cambridge: Cambridge University Press.

Peet, Richard. 1979. Societal contradiction and Marxist geography. Annals of the Association of American Geographers 69(1), 164-169.

Sahlins, Marshall. 1977. The Use and Abuse of Biology: An Anthropological Critique of Sociobiology. Ann Arbor: The University of Michigan Press. 